\title{
Effects of various winter chilling regimes on flowering quality indicators of Greek olive cultivars
}

\author{
G. KOUBOURIS*, I. LIMPERAKI, M. DARIOTI, and C. SERGENTANI \\ Institute of Olive Tree, Subtropical Crops and Viticulture, Hellenic Agricultural Organization DEMETER, \\ Leoforos Karamanli 167, 73100 Chania, Greece
}

\begin{abstract}
Aims of the present two-year study were to evaluate the feasibility and identify potential drawbacks of the greenhouse/ outdoors parallel plant growth methods for investigation of the effects of various winter chilling regimes on flowering quality indicators of four Greek olive cultivars, namely Mastoidis, Amfissis, and Lefkolia Serron (originating from mountainous and colder areas) compared to cv. Koroneiki (grown mainly in plain warm areas). Groups of potted olive plants were either grown outdoors under ambient temperature or transferred into a greenhouse for one, two, or three months during winter in Crete, Greece. During the first year, chilling accumulation deficit caused a marked decrease in the number of inflorescences per plant in all four olive cultivars. In the second year, chilling accumulation deficit had a negative effect on the number of inflorescences per plant in 'Mastoidis' at 3-month greenhouse treatment but not at all in 'Koroneiki'. Chilling deficit caused an overall decrease in the number of flowers per inflorescence in both 'Koroneiki' and 'Mastoidis' as well as in the percentage of morphologically perfect flowers. The width and length of inflorescences were not affected by chilling deficit in both the cultivars. In vitro pollen germination was reduced in all greenhouse treatments in 'Koroneiki'; however, this effect was significant only after 3 month, whereas no effect was observed in 'Mastoidis'. The results of the present study may contribute to understanding olive flowering biology and selecting appropriate cultivars for new plantations according to historical meteorological data and predicted climate change scenarios.
\end{abstract}

Additional key words: climate change, ovary abortion, phenology, pollen germination, vernalization.

\section{Introduction}

Olive (Olea europaea L.) is one of the most important crops in Mediterranean countries where over a $90 \%$ of global olive production is realized (International Olive Council, http:www.internationaloliveoil.org/). Olive tree is cultivated for the production of olive oil (juice extracted from the fruit by natural means) and for table olives (edible fruit after mild treatment to remove bitter taste and increase preservation time) both consumed and highly appreciated for their nutritional value and health benefits (Accardi et al. 2016, Agrawal et al. 2017). Additional products of olive tree with an economic and health promoting value are its wood (Santos et al. 2017) and leaves (Rahmanian et al. 2015), respectively. Last but not least, sustainably managed olive groves may provide significant ecosystem services in the environmentally fragile Mediterranean region (Montanaro et al. 2017).

Climate change is expected to have significant impacts in Mediterranean basin agriculture and the environment
(Milano et al. 2013). Indeed, temperature increase, water deficiency, and extreme climatic events are the main components of the changing climate (Giannakopoulos et al. 2009, Kourgialas et al. 2019). Crops may thus suffer serious yield reduction as well as plant damage (Koubouris 2018).

For each plant species, there is a temperature range which is suitable for its survival and a narrower temperature range which favors its optimal growth and flowering. Outside this temperature range, plants underperform and may face serious damages, and in an extreme or long term exposure, they may die. For example, an olive tree physiological and reproductive performance may be at risk at temperatures over $35-40{ }^{\circ} \mathrm{C}$ (Koubouris et al. 2009, 2015a,b). Similarly, olive plants face negative changes both at their reproductive and at physiological functions when air temperature drops below -7 and $-12{ }^{\circ} \mathrm{C}$, respectively (Pallioti and Bongi 1996, Barranco et al. 2005).

Plants often employ a physiological mechanism called dormancy (expressed as vegetative growth arrest and often

Submitted 26 February 2019, last revision 30 March 2019, accepted 4 April 2019.

Abbreviations: C - control plants grown outdoors under natural environment; CR - chilling requirement; HSD - honestly significant difference; $1 \mathrm{M}, 2 \mathrm{M}, 3 \mathrm{M}$ - plants grown in an unheated glasshouse for 1, 2, or 3 winter months.

Acknowledgements: This research has been financed by Greek national funds through the Action 'Establishment of a National Research

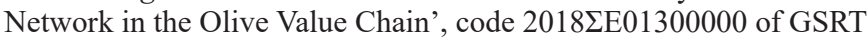

* Corresponding author; e-mail: koubouris@nagref-cha.gr 
leaf dehiscence) to survive during the cold winter period and avoid frost damage (Ramos et al. 2018). However, low winter temperatures (e.g., above $1.5^{\circ} \mathrm{C}$ and below 16 $19^{\circ} \mathrm{C}$ ), may have beneficial effects on plant biological cycle (Cesaraccio et al. 2004). In fact, many plant species demand certain exposure to low temperature during winter to overcome dormancy and to be able to develop flowers in the subsequent spring (Campoy et al. 2011).

However, dormancy release seems to be affected also by other factors aside temperature. Water deficit during the cold period of the year was found to substitute chilling effect for breaking dormancy in Peru where precipitation is mainly realized during the warm period of the year (Connor and Ferreres 2005). On the other hand, the hypothesis that increased precipitation shortens the dormancy period in fruit trees was also suggested (Sfakiotakis 1993) implying that vernalization mechanisms may differ between plant species.

The chilling requirement (CR; duration of plant exposure to effective chilling temperatures) may differ quantitatively as well as qualitatively (temperature and plant phenological stage) between plant species, varieties, and growing regions (Li et al. 2016).

The olive tree develops flowers during spring on shoots that have been formed during the previous vegetative period. Several factors, such as a genotype, duration of winter chilling previous year's fruit load, nutritional and water balance, as well as other crop management practices and environmental components, affect flowering abundance and quality (Fabbri and Benelli 2000). For example, it has been reported that olive trees growing at a temperature constantly higher than $15.5^{\circ} \mathrm{C}$ do not produce any flowers (Hartmann and Porlinglis 1957). Indeed, the failure of olive plantations to flower and yield fruit, when established in areas with warm winter, confirms that olive tree requires chilling for dormancy release (De MeloAbreu et al. 2004). In a recent study, olive flower induction was shown to be regulated by the expression of the Flowering locus T gene (Haberman et al. 2017).

Reasonably, not all olive cultivars have similar chilling demands (Gabaldon-Leal et al. 2017). For example, cv. Leccino was considered to have higher needs in chilling accumulation compared to Arbequina and Frantoio (Aybar et al. 2015). Similarly, some olive cultivars, such as Sevillano and Ascolana are considered to have a very high CR (Kailis and Harris 2007), whereas in North African countries, local olive cultivars grow and produce sufficient yields under hot environmental conditions (Acila et al. 2017). There is also a debate on the efficiency of different temperatures for chilling accumulation and break of dormancy, e.g., $7^{\circ} \mathrm{C}$ was initially considered as optimal (Hartman and Porlingis 1957), but a higher temperature of $12.5^{\circ} \mathrm{C}$ was suggested more recently (Ramos et al. 2018).

Climate change predictions related to temperature increase in the Mediterranean region estimate that chilling accumulation units will be reduced for some of the most important crops such as peach, apple, grape, and olive (Perez Lopez et al. 2012). Since olive is grown in many areas with highly variable climate and winter temperature range, caution should be paid to select appropriate cultivars that meet $\mathrm{CR}$ and produce sufficient fruit yields.

Aims of the present study were: 1) to evaluate the feasibility and identify potential drawbacks of the greenhouse/outdoors parallel plant growth as a method for chilling accumulation studies and 2) to investigate the effects of various winter chilling regimes on flowering quality indicators of Greek olive cultivars naturally grown or cultivated in different environments.

\section{Materials and methods}

Plants and growth conditions: The present two-year study was implemented in the Institute of Olive Tree, Subtropical Crops and Viticulture in Chania, Greece (latitude $35^{\circ}$; longitude $23^{\circ}$; altitude $28 \mathrm{~m}$ a.s.1.). During the first year, a preliminary trial with four olive cultivars was implemented. Eighty (two-year-old) potted plants of cultivars Mastoidis (grown in southern Greece), Amfissis (grown in central Greece), Lefkolia Serron (grown in northern Greece), and Koroneiki (grown mainly in plain areas with warm climate and produces satisfactory yields even in the hot climate of North African countries). They were separated in 5-item groups. All inflorescences were removed during spring to avoid alternate bearing effect and plants were routinely cultured until autumn in an open nursery. At the end of November, three groups of plants for each cultivar were transferred in an unheated glasshouse with a north-south orientation for 1, 2, or 3 winter months and one group of plants for each cultivar was grown outdoors under natural environmental conditions (Fig. 1 Suppl.) to simulate winter temperature variation and to study its effect on subsequent flowering. Treatments are named as $1 \mathrm{M}, 2 \mathrm{M}, 3 \mathrm{M}$, and $\mathrm{C}$, throughout the paper.

During the second year, the experiment was repeated for 'Koroneiki' and 'Mastoidis' based on the results of the first year (abundant and stable flowering in the control plants in contrast with an intrinsic poorer and unstable flowering in 'Amfissis' and 'Lefkolia Serron', which might interfere with the effect of chilling accumulation on flowering - details in the Discussion). Forty (three-year-old) potted plants were separated in five-item groups and steps described in the previous paragraph were followed. A thermograph was employed for monitoring the air temperature inside the glasshouse and the adjacent meteorological station for the ambient temperature outdoors. A gap in outdoors temperature record was observed around the year change due to a temporal failure in the meteorological station which was then fixed. A simplified method to assess chilling accumulation was devised; for each treatment and cultivar, the total number of hours below $16{ }^{\circ} \mathrm{C}$ during the study period was recorded. The maximum threshold temperature of $16{ }^{\circ} \mathrm{C}$ was selected according to Aguilera et al. (2014) since above this limit, no chilling accumulation is realized. In the present study, plants grown outdoors under natural environmental conditions received $1835 \mathrm{~h}$ below $16{ }^{\circ} \mathrm{C}$ during the three winter months (Fig. 2 Suppl.). Plants grown in the glasshouse for 1,2 , or 3 winter months received 1663,1497 , and 1214 h below $16^{\circ} \mathrm{C}$, respectively. 
Phenology and floral quality measurements: During the preliminary trial of the first year, in April, we determined the percentage of plants with complete absence of flowering and for the flowered plants, the number of inflorescences per plant. In the main experiment of the second year, in the following spring, flowering phenology was recorded according to Sanz-Cortes et al. (2002) as well as qualitative and quantitative flowering quality indicators, namely: a) the percentage of plants with total absence of flowering, b) for the flowering plants, the number of inflorescences per plant, $c$ ) the number of flowers/inflorescence, $d$ ) the percentage of morphologically perfect flowers (with pistil and stamen), e) the length of inflorescence, and $f$ ) the width of inflorescence. Finally, a destructive sampling of inflorescence was implemented for subsequent laboratory measurements

In vitro pollen germination: In order to assess pollen performance of plants grown at various winter chilling regimes, pollen was collected from freshly opened flowers and subsequently incubated at room temperature $\left(\sim 25^{\circ} \mathrm{C}\right)$ in the dark in a growth chamber (Kottermann 2770, D3162; Hanigsen, Germany) for $24 \mathrm{~h}$ before counting pollen germination and pollen tube length according to Koubouris et al. (2015b). Throughout the experiment, pollen was cultured on a solid medium consisting of $0.8 \%$ $(\mathrm{m} / \mathrm{v})$ agar, $15 \%(\mathrm{~m} / \mathrm{v})$ sucrose, $1.64 \mathrm{mM}$ boric acid, and $60 \mathrm{mg} \mathrm{dm}^{-3}$ tetracycline hydrochloride according to Koubouris et al. (2009). Pollen germination was evaluated on 4 Petri dish fields containing over 50 pollen grains for each treatment.

Statistical analysis: Data were analyzed using SPSS (SPSS Inc., Chicago, USA) and were subjected to one-way analysis of variance. Significantly different means were calculated at $P \leq 0.05$ using the Tukey honestly significant difference test.

\section{Results}

During the first year, reduced winter chilling caused a marked decrease in the number of inflorescences per plant in all four olive cultivars (Fig. 1A). These results are statistically significant $(P<0.05)$ for 'Koroneiki' (3M), 'Mastoidis' $(2 \mathrm{M}+3 \mathrm{M})$ and 'Lefkolia Serron'(2M) treatments. In the case of 'Amfissis', there were no statistically significant differences in spite of the total absence of flowers in treatments $2 \mathrm{M}+3 \mathrm{M}$, potentially due to high variations among plants (Fig. 1A). In 'Koroneiki', plants without flowers were observed only in $3 \mathrm{M}$, in 'Mastoidis' in all greenhouse treatments whereas in 'Lefkolia Serron'and 'Amfissis' in all four treatments (Fig. $1 B)$.

In the second year, chilling accumulation deficit had a negative effect $(P<0.05)$ on the number of inflorescences per plant in 'Mastoidis' at 3M but not at all in 'Koroneiki' (Fig. 2A). The incidence of plants with a complete absence of flowers was observed in $1 \mathrm{M}$ and $2 \mathrm{M}$ in 'Koroneiki' and
$1 \mathrm{M}$ and $3 \mathrm{M}$ in 'Mastoidis', whereas all outdoors grown plants successfully formed flowers in both cultivars (Fig. 2B).

Chilling deficit through maintaining plants inside the greenhouse for various time intervals of winter caused an earlier inflorescence buds swelling compared to the control in 'Koroneiki' (Fig. 3). However, in the case of 'Mastoidis', the effect was variable, and we observed no clear trend. In the end, the date of flower opening was not affected by the treatments but mostly by the cultivar.

Chilling deficit caused an overall decrease in the number of flowers per inflorescence in both cultivars; however, this effect was statistically significant $(P<0.05)$ only in the case of $1 \mathrm{M}$ in 'Mastoidis' (Fig. 4A). The percentage of morphologically perfect flowers (with pistil and stamen) was significantly reduced $(P<0.05)$ in 'Koroneiki' at $3 \mathrm{M}$ (Fig. $4 B$ ). In the case of 'Mastoidis', a reduction was observed at $2 \mathrm{M}$ and $3 \mathrm{M}$ but it was statistically significant $(P<0.05)$ only at $2 \mathrm{M}$. Inflorescence width and length were not affected by chilling deficit in both cultivars (Fig. 4C,D). In vitro pollen germination was reduced in all greenhouse treatments in 'Koroneiki', however, this

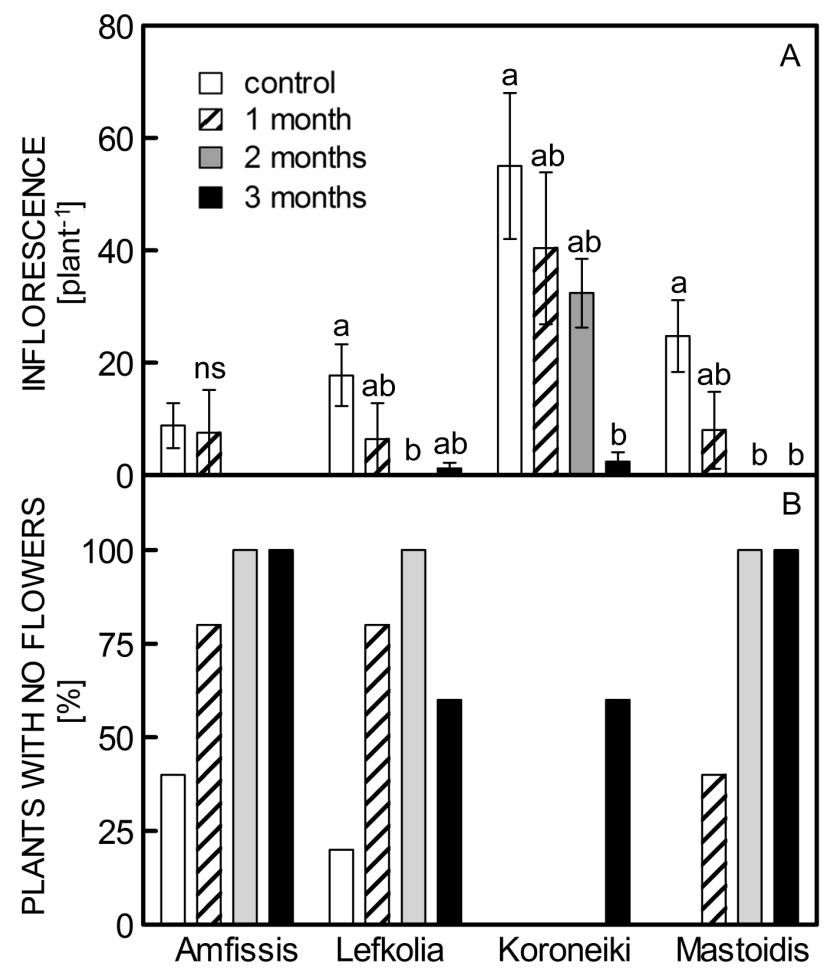

Fig. 1. Effect of winter chilling deficit (potted plants transferred for 1,2 , or 3 months in a greenhouse) during the first year on the number of inflorescences per plant $(A)$ and the percentage of plants with total absence of flowers $(B)$ in olive cultivars Amfissis, Lefkolia Serron, Koroneiki, and Mastoidis. Means \pm SEs, $n=5$, significantly different means marked with different letters in $A$ were calculated at $P \leq 0.05$ using the Tukey honestly significant difference test. Statistical analysis was not feasible for $B$. 


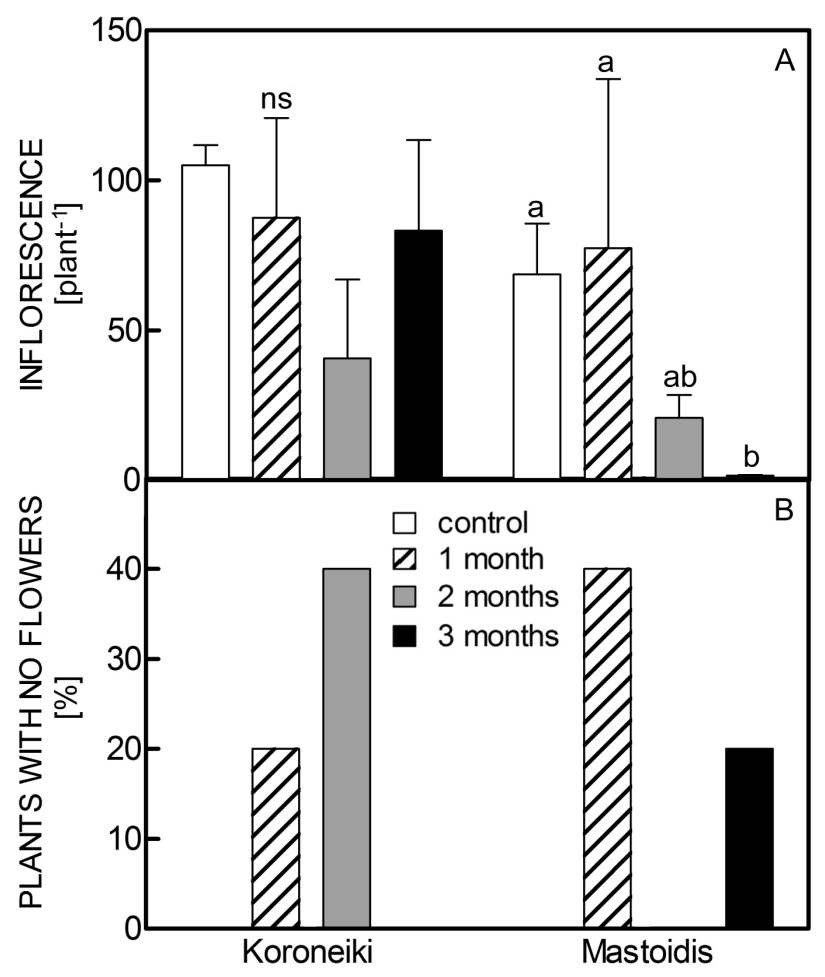

Fig. 2. Effect of winter chilling deficit (potted plants transferred for 1, 2 or 3 months in a greenhouse) during the second year on the number of inflorescences per plant $(A)$ and the percentage of plants with total absence of flowers $(B)$ in olive cultivars Koroneiki and Mastoidis. Means \pm SEs, $n=5$, significantly different means marked by different letters in $A$ were calculated at $P \leq 0.05$ using the Tukey honestly significant difference test. Statistical analysis was not feasible for $B$.

effect was significant $(P<0.05)$ only at $3 \mathrm{M}$, whereas no significant effect was observed in 'Mastoidis' (Fig. 5).

\section{Discussion}

Olive is the major tree crop in Greece and it is cultivated in a vast variety of microclimatic conditions as, for example, the hot, arid southern part of the country on the island Crete up to the rather cold northwestern areas such as Alexandroupoli near borders with Turkey and Bulgaria. In spite of the germplasm richness available in Greece, estimated around 100 cultivars, basic genetic and morphological data are available for less than 40 of them (Koubouris et al. 2019), and chilling requirements have been estimated only for 'Koroneiki' in the environmental conditions of Andalusia, Spain (Gabaldón-Leal et al. 2017).

Plants grown in the glasshouse for 1,2 , or 3 winter months were exposed to reduced chilling hours of $-9 \%(\mathrm{M} 1),-18 \%$ (M2) and $-34 \%$ (M3), compared to the control. There seems to be differentiation among treatments achieved by our experimental design. Also, the temperature fluctuation inside the greenhouse followed the trend of ambient conditions observed outdoors providing a more realistic environment for chilling accumulation

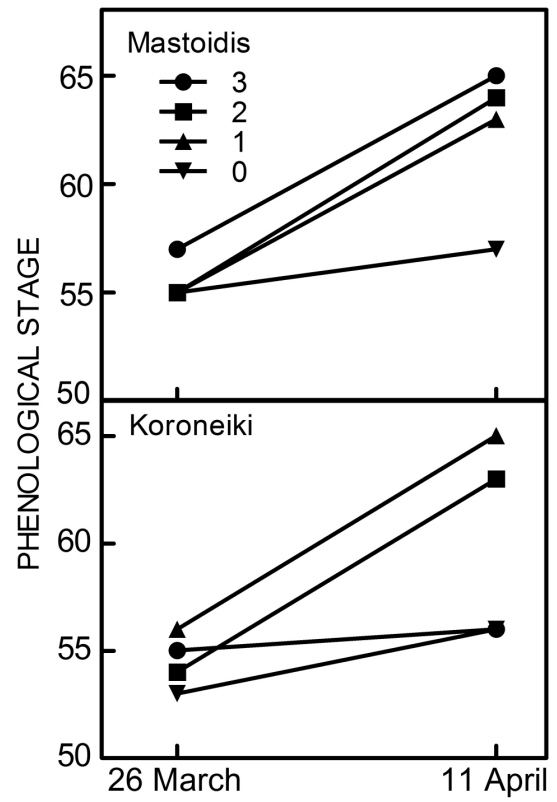

Fig. 3. Effect of winter chilling deficit (potted plants transferred for 1, 2 or 3 months to a greenhouse) during the second year on flowering phenology in olive cultivars Koroneiki and Mastoidis based on the scale of Sanz-Cortes et al. (2002) $(n=5)$.

studies compared to studies at growth chambers where the temperature is set to be almost stable throughout the day (Ramos et al. 2018). When even a higher accuracy in environmental conditions is desired, the suggested strategy is to employ open-top chambers with artificial temperature control as successfully tested by Benlloch-Gonzalez et al. (2018). Another available method for chilling accumulation studies would be sampling explants and forcing them in growth chambers under the desired temperature regimes (Ramos et al. 2018). In any case, it should be noted that variation of day/night temperatures plays a role in chilling accumulation efficiency since maintaining plants in a constant temperature of $7{ }^{\circ} \mathrm{C}$ results in minimal flowering (Denney and McEachern 1983).

The percentage of plants with an absolute absence of flowers provides another very interesting insight regarding genotypic response to a chilling deficit. Due to the presence of plants with no flowering even in the control plants during the first year, 'Lefkolia Serron' and 'Amfissis' were considered to have intrinsic poor flowering and thus excluded from the second year experiment. This finding might also be an indication of high CR of these olive cultivars, which was not fulfilled even in the plants grown outdoors in the mild winter conditions of Crete. Therefore, in future trials, a higher chilling accumulation should be achieved in the control plants, either by selecting a site with lower temperature regime or by artificially regulating environmental conditions. During the second year of the present study, the incidence of plants with no flowers varied between cultivars but being zero in the control plants of both cultivars ('Koroneiki' and 'Mastoidis') provides a quality assurance indicator for the experiment. Growing olive plants constantly over $16^{\circ} \mathrm{C}$ in a greenhouse results in a complete absence of inflorescence in other 


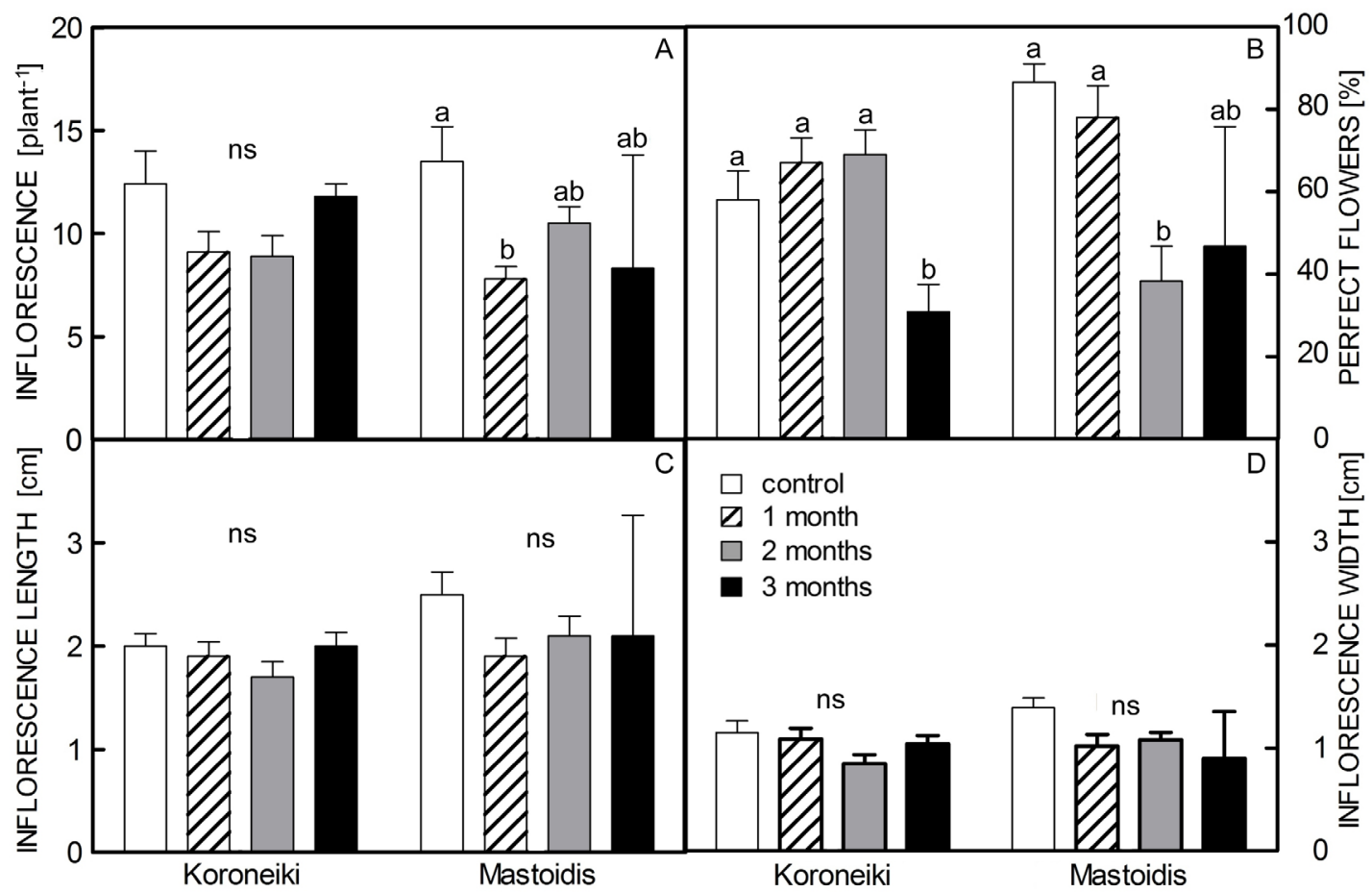

Fig. 4. Effect of winter chilling deficit (potted plants transferred for 1, 2 or 3 months in a greenhouse) during the second year on the number of flowers per inflorescence $(A ; n=20)$, the percentage of morphologically perfect flowers with pistils and stamens $(B ; n=$ $100)$, inflorescence length $(C ; n=20)$, and inflorescence width $(D ; n=20)$ in olive cultivars Koroneiki and Mastoidis. Means \pm SEs, significantly different means marked by different letters were calculated at $P \leq 0.05$ using the Tukey honestly significant difference test.

cultivars (Hackett and Hartman 1967). A reduced number of flowers per inflorescence and a reduced percentage of perfect flowers due to chilling deficit observed in the present work are in agreement with previous studies in other olive cultivars, e.g., absence or asynchronous flowering in new olive growing areas (Castillo-Llanque et al. 2014, Aybar et al. 2015) as well as a reduced number of inflorescence and an increased ovary abortion (Deng et al. 1988) may be related to chilling accumulation deficit of the grown cultivars as reported in Ramos et al.

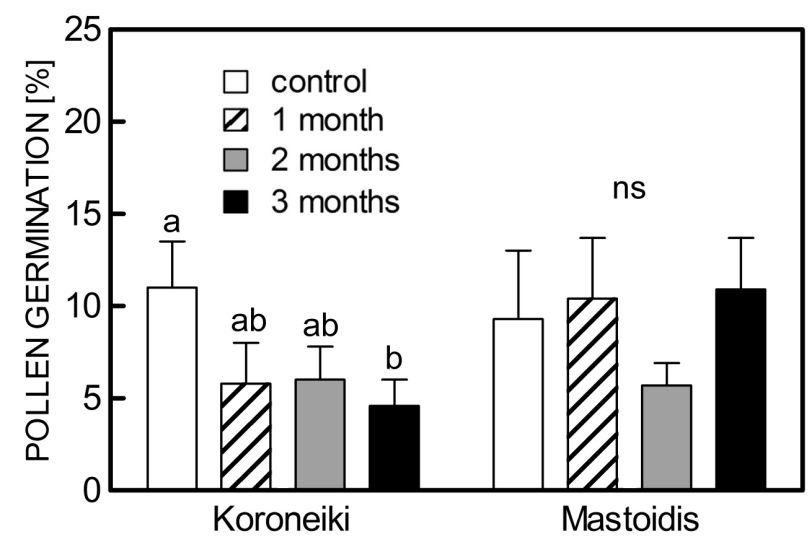

Fig. 5. Effect of winter chilling deficit (potted plants transferred for 1, 2 or 3 months in a greenhouse) during the second year on in vitro pollen germination from olive cultivars Koroneiki and Mastoidis. Means \pm SEs, $n=200$, significantly different means marked by different letters were calculated at $P \leq 0.05$ using the Tukey honestly significant difference test.
(2018). However, during springtime, when CR fulfillment has been completed and inflorescence approach anthesis, low-temperature incidents may have negative impacts on flowering and fruit set of olive (Koubouris et al. 2010a).

In the present study, the effect of chilling deficit reached by maintaining plants inside the greenhouse for various time intervals of winter caused an earlier inflorescence buds swelling in 'Koroneiki', probably due to higher thermal units accumulation compared to the control plants grown outdoors, following chilling accumulation demand fulfillment as also observed in multiple sites of Spain, Italy, and Tunisia by Aguilera et al. (2014). However, in the end, the date of flowering was not affected by the chilling treatments but only depended on the cultivar as was also previously demonstrated for these cultivars (Koubouris et al. 2010b). This is also supported by the fact that from $1^{\text {st }}$ March and onward, all plants were grown outdoors in identical environmental conditions and management practices. It was therefore reasonable that inflorescence length and width were similar in all treatments of each cultivar since these features are mainly regulated by thermal accumulation, water and nutrition balance, and other factors rather than CR (Cuevas et al. 1994, Acebedo et al. 2000, Rapoport et al. 2012, Aguilera et al. 2014). Similarly, minor differences observed here in pollen germination after different treatments are unlikely to be related to the chilling deficit but probably should be further studied in future experiments.

Some important effects of winter chilling deficit on flowering quality indicators of major Greek olive cultivars were elucidated in the present study. Multiyear 
and multisite trials with enriched germplasm coupled with flowering-related gene expression analysis (Haberman et al. 2017) are in progress to provide precious knowledge on olive flowering biology and contribute to selecting appropriate cultivars for new plantations according to historical meteorological data and predicted climate change scenarios.

\section{References}

Accardi, G., Aiello, A., Gargano, V., Gambino, C.M., Caracappa, S., Marineo, S., Vesco, G., Carru, C., Zinellu, A., Zarcone, M., Caruso, C., Candore, G.: Nutraceutical effects of table green olives: a pilot study with Nocellara del Belice olives. Immun. Ageing 13: 11, 2016.

Acebedo, M.M., Cañete, M.L., Cuevas J.: Processes affecting fruit distribution and its quality in the canopy of olive trees. Adv. hort. Sci. 14: 169-175, 2000.

Acila, S., Saker, M.L., Bouhoun, M.D., Taamalli, A., Ould El Hadj, M.D., Zarrouk, M.: An alternative assessment of olive (Olea europaea L.) cultivars adaptation in the Mediterranean Saharan context of Algeria. - J. appl. Hort. 19: 51-57, 2017.

Agrawal, K., Melliou, E., Li, X., Pedersen, T.L., Wang, S.C., Magiatis, P., Newman, J.W., Holt, R.R.: Oleocanthal-rich extra virgin olive oil demonstrates acute anti-platelet effects in healthy men in a randomized trial. - J. funct. Food 36: 8493, 2017.

Aguilera, F., Ruiz, L., Fornaciari, M., Romano, B., Galan, C., Oteros, J., Dhiab, A.B., Msallem, M., Orlandi, F.: Heat accumulation period in the Mediterranean region: phonological response of the olive in the different climate areas (Spain, Italy and Tunisia). - Int. J. Biometeorol. 58: 867876, 2014.

Aybar, V., De Melo-Abreu, J.P., Searles, P.S., Matias, A.C., Del Río, C., Caballero, J.M., Rousseaux, M.C.: Evaluation of olive flowering at low latitude sites in Argentina using a chilling requirement model. - Spanish J. agr. Res. 13: e09-001, 2015.

Barranco, D., Ruiz N., Gomez-del Campo, M.: Frost tolerance of eight olive cultivars. - HortScience 40: 558-560, 2005.

Benlloch-González, M., Sánchez-Lucas, R., Benlloch, M., Ricardo, F.E.: An approach to global warming effects on flowering and fruit set of olive trees growing under field conditions. - Sci. Hort. 240: 405-410, 2018.

Campoy, J.A., Ruiz, D., Egea, J.: Dormancy in temperate fruit trees in a global warming context: a review. - Sci. Hort. 130: 357-372, 2011.

Castillo-Llanque, F.J., Rapoport, H.F., Baumann Samanez, H.: Irrigation withholding effects on olive reproductive bud development for conditions with insufficient winter chilling. Acta hort. 1057: 113-119, 2014.

Cesaraccio, C., Spano, D., Snyder, R.L., Duce, P.: Chilling and forcing model to predict bud-burst of crop and forest species. - Agr. Forest Meteor. 126: 1-13, 2004.

Connor, D.J., Ferreres, E.: The physiology and yield expression in olive. - Hort. Rev. 31: 155-230, 2005.

Cuevas, J., Rallo, L., Rapoport, H.F.: Crop load effects on floral quality in olive. - Sci. Hort. 59: 123-130, 1994.

De Melo-Abreu, J.P., Barranco, D., Cordeiro, A.M., Tous, J., Rogado, B.M., Villalobos, F.J.: Modelling olive flowering date using chilling for dormancy release and thermal time. Agr. Forest Meteorol. 125: 117-127, 2004.

Deng, M.Q., Zhao, L.H., Zhu, C.J.: The relation of flower bud differentiation in olive to climate and new shoot growth. - Sci. silvae sin. 24: 393-398, 1988.

Denney, J.O., McEachern, R.: An analysis of several climatic temperature variables dealing with olive reproduction. - J. amer. Soc. hort. Sci. 108: 578-581, 1983.

Fabbri, A., Benelli, C.: Flower bud induction and differentiation in olive. - J. hort. Sci. Biotechnol. 75: 131-141, 2000.

Gabaldón-Leal, C., Ruiz-Ramos, M., De la Rosa, R., León, L., Belaj, A., Rodríguez, A., Santos, C., Lorite, I.J.: Impact of changes in mean and extreme temperatures caused by climate change on olive flowering in southern Spain. - Int. J. Climatol. 37: 940-957, 2017.

Giannakopoulos, C., Le Sager, P., Bindi, M., Moriondo, M., Kostopoulou, E., Goodess, C.M.: Climatic changes and associated impacts in the Mediterranean resulting from a $2{ }^{\circ} \mathrm{C}$ global warming. - Global Planet Change 68: 209-224, 2009.

Haberman, A., Bakhshian, O., Cerezo-Medina, S., Paltiel, J., Adler, C., Ben-Ari, G., Mercado, J.A., Pliego-Alfaro, F., Lavee, S., Samach, A.: A possible role for FT encoding genes in interpreting environmental and internal cues affecting olive (Olea europaea L.) flower induction. - Plant Cell Environ. 40: 1263-1280, 2017.

Hackett, W.P., Hartman, H.T.: The influence of temperature on floral initiation in the olive. - Physiol. Plant. 20: 430-436, 1967.

Hartman, H., Porlingis, I.: Effect of different amounts of winter chilling on fruitfulness of several olive varieties. - Bot. Gaz. 119: 102-104, 1957.

Kailis, S., Harris, D.: Producing Table Olives. - Landlinks Press, Collingwood 2007.

Koubouris, G.: Editorial - Advances in prediction, monitoring and mitigation of climate change effects on water resources and good agricultural practices for crop adaptation to environmental stresses. - J. Water Climat Change 9: 631-632, 2018.

Koubouris, G.C., Avramidou, E.V., Metzidakis, I.T., Petrakis, V.P., Sergentani, C.K., Doulis. A.G.: Phylogenetic and evolutionary applications of analyzing endocarp morphological characters by classification binary tree and leaves by SSR markers for the characterization of olive germplasm. - Tree Genet. Genom. 15: 26, 2019.

Koubouris, G.C., Kavroulakis, N., Metzidakis, I.T., Vasilakakis, M.D., Sofo, A.: Ultraviolet-B radiation or heat cause changes in photosynthesis, antioxidant enzyme activities and pollen performance in olive tree. - Photosynthetica 53: 279-287, 2015a.

Koubouris, G.C., Metzidakis, I.T., Vasilakakis, M.D.: Impact of temperature on olive (Olea europaea L.) pollen performance in relation to relative humidity and genotype. - Environ. exp. Bot. 67: 209-214, 2009.

Koubouris, G.C., Metzidakis, I.T., Vasilakakis, M.D.: Influence of cross pollination on the development of parthenocarpic shotberries - olive (Olea europaea L.) fruits. - Exp. Agr. 46: 67-76, 2010a.

Koubouris, G.C., Metzidakis, I.T., Vasilakakis, M.D.: Phenological, morphological and functional indicators of genetic variability and their implication in the sexual reproductive system of Olea europaea L. (Oleaceae). - Sci. Hort. 123: 547-550, 2010b.

Koubouris, G.C., Tzortzakis, N., Kourgialas, N., Darioti, M., Metzidakis, I.T.: Growth, photosynthesis and pollen performance in saline water treated olive (Olea europaea L.) plants under high temperature. - Int. J. Plant Biol. 6: 6038, 28-32, 2015b.

Kourgialas, N., Koubouris, G., Dokou, Z.: Optimal irrigation planning for addressing current or future water scarcity in Mediterranean tree crops. - Sci. total Environ. 654: 616-632, 
2019.

Li, Y., Fang, W.C., Zhu, G.R., Cao, K., Chen, C.W., Wang, X.W., Wang, L.R.: Accumulated chilling hours during endodormancy impact blooming and fruit shape development in peach (Prunus persica L.). - J. integr. Agr. 15: 1267-1274, 2016.

Milano, M., Ruelland, D., Fernandez, S., Dezetter, A., Fabre, J., Servat, E., Fritsch, J.M., Ardoin-Bardin, S., Thivet, G.: Current state of Mediterranean water resources and future trends under climatic and anthropogenic changes. - Hydrol. Sci. J. 58: 498-518, 2013.

Montanaro, G., Xiloyannis, C., Nuzzo, V., Dichio, B.: Orchard management, soil organic carbon and ecosystem services in Mediterranean fruit tree crops. - Sci. Hort. 217: 92-101, 2017.

Palliotti, A., Bongi, G.: Freezing injury in the olive leaf and effects of mefluidide treatment. - J. hort. Sci. 71: 57-63, 1996.

Pérez López, D., Ruiz Ramos, M., Sánchez, E., Centeno Muñoz, A., Prieto Egido, I., López de la Franca, N.: Influence of Climate Change on the Flowering of Temperate Fruit Trees. EGU2012-5774, EGU General Assembly, Vienna 2012.

Rahmanian, N., Jafari, S.M., Wani, T.A.: Bioactive profile, dehydration, extraction and application of the bioactive components of olive leaves. - Food Sci. Technol. 42: 150-172, 2015.

Ramos, A., Rapoport, H.F., Cabello, D., Rallo, L.: Chilling accumulation, dormancy release temperature, and the role of leaves in olive reproductive budburst: evaluation using shoot explants. - Sci. Hort. 231: 241-252, 2018.

Rapoport, H.F., Hammami, S.B.M., Martins, P., Pérez-Priego, O., Orgaz, F.: Influence of water deficits at different times during olive tree inflorescence and flower development. - Environ. exp. Bot. 77: 227-233, 2012.

Santos, J.I., Fillat, Ú., Martín-Sampedro, R., Eugenio, M.E., Negro, M.J., Ballesteros, I., Rodríguez, A., Ibarra, D.: Evaluation of lignins from side-streams generated in an olive tree pruning-based biorefinery: bioethanol production and alkaline pulping. - Int. J. Biol. Macromol. 105: 238-251, 2017.

Sanz-Cortes, F., Martinez-Calvo, J., Badenes, M.L., Bleiholder, H., Hack, H., Llacer, G., Meier, U.: Phenological growth stages of olive trees (Olea europaea). - Ann. appl. Biol. 140: 151-157, 2002.

Sfakiotakis, E.: General Pomology. - Typo Man Publishing, Thessaloniki 1993. 